\title{
An Unusual Presentation of Lepromatous Leprosy
}

\author{
Dr S Gupta*, Col A Mehta ${ }^{+}$Col R Lakhtakia\#, Brig SK Nema**
}

MJAFI 2006; 62 : 392-393

Key Word: Lepromatous leprosy

\section{Introduction}

\begin{abstract}
n estimated 1.34 million cases of leprosy occur Aworldwide and 7.53 lakh cases are on record globally with a prevalence rate of 1.25 per 10,000 population [1]. India accounts for $60.9 \%$ of globally recorded cases of leprosy. The prevalence rate is 5.0 per 10,000 population [1]. Mycobacterium leprae (M leprae) is a unique organism with capacity to invade not only Schwann cells but also other parenchymal tissues such as testis, lymph node, larynx, liver, spleen, bone marrow, bone and muscle [2].
\end{abstract}

We report a case of leprosy with initial presentation of myositis followed by skin lesions and lymphadenopathy. Its rarity coupled with the diagnostic problem it poses, on account of its unusual location, makes it unique.

\section{Case Report}

A 28 year old male presented with a history of pain in the muscles of both lower limbs of four months duration. A muscle biopsy performed from lateral head of gastrocnemius was reported as non-specific myositis. On a later review he was found to be having rheumatic heart disease with mitral stenosis and mitral regurgitation. The muscle nodules were clinically diagnosed as erythema nodosum. One month later, a magnetic resonance image (MRI) scan of the muscle showed anoxic muscle damage involving medial and lateral heads of gastrocnemius (Fig 1). FNAC of nodular lesions showed fibroblastic proliferation consistent with anoxic muscle injury.

At this time, he was noted to have enlarged right posterior cervical and axillary lymph nodes. Lymph node biopsy was performed which revealed involvement by lepromatous leprosy. Three months later he developed multiple, bilaterally symmetrical, erythematous, ill defined, hyperpigmented macular lesions on legs, thighs and forearms. A skin biopsy confirmed the diagnosis of lepromatous leprosy. A review of the earlier muscle biopsy revealed lepromatous involvement of skeletal muscle.

Histopathological findings of lymph node biopsy showed preserved lymph node follicular architecture. There were focal collections of foamy macrophages interspersed with plasma cells with acid fast bacilli-lepra [AFB(L)] bacilli in globi (Fig. 2a). The skin biopsy showed sheets of foamy macrophages in the dermis with a sprinkling of lymphocytes (Fig. 2b). FiteFaraco stain revealed numerous AFB(L).

The muscle biopsy showed marked destruction of myofibres with replacement by a diffuse foam cell-rich, lymphocyte-poor infiltrate. Lepra bacilli in globi were seen in the foam cells (Fig. 3). A diagnosis of lepromatous leprosy involving lymph node, skin and muscle was made.

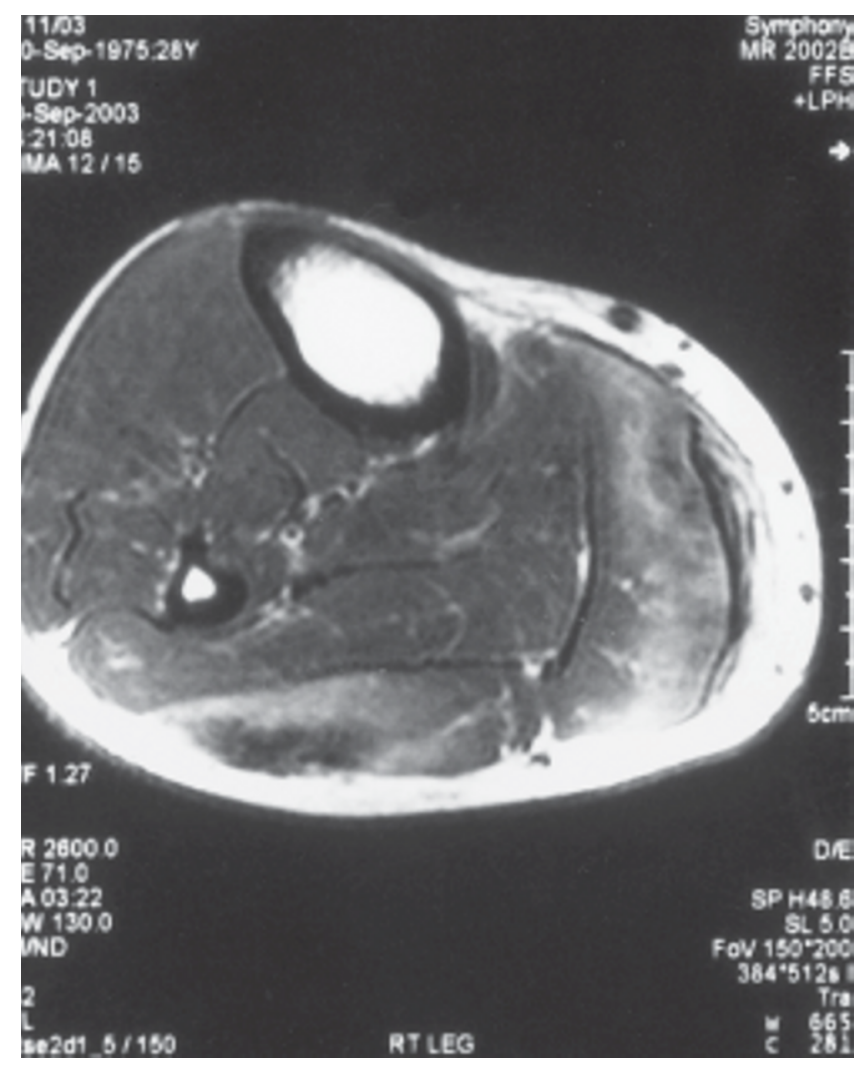

Fig. 1: T2 weighted image of lower limb on MRI shows mixed intensity lesions in both heads of gastrocnemius consistent with anoxic muscle damage.

"Resident, ${ }^{+}$Professor and HOD, ( (Department of Pathology), AFMC, Pune. "Senior Advisor (Pathology), *'Deputy Commandant, $\mathrm{CH}(\mathrm{CC})$, Lucknow 


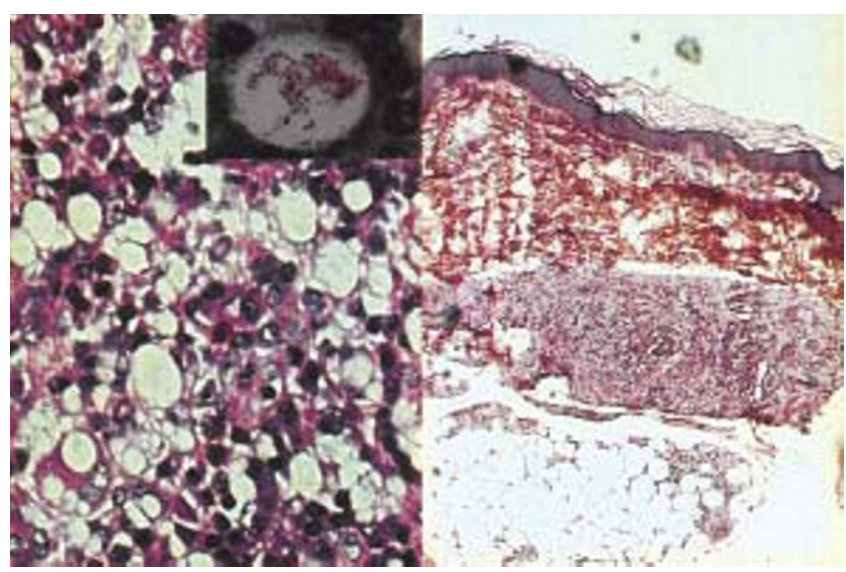

Fig. 2 : a) Lymph node showing clusters of foam cells with scattered lymphocytes and plasma cells (H\&E x 40). Inset numerous AFB (L) present as globi in the foam cells (Fite-Faraco stain $\mathrm{x}$ 100)

b) Skin biopsy shows diffuse foam cell rich granulomas in the reticular dermis $(\mathrm{H} \& \mathrm{E} \times \mathrm{4})$

\section{Discussion}

Mycobacterium leprae infection usually presents with cutaneous and neurological involvement. However, initial clinical manifestation in muscle, lymph node, larynx, liver, spleen, bone marrow, bone and testes (proven by biopsy) has been infrequently reported [2].In pure neuritic leprosy patient may not show any skin lesion [3]. Occasionally musculoskeletal involvement precedes characteristic cutaneous and / or neural involvement [4]. The involvement of skeletal muscle in leprosy is considered secondary to peripheral nerve involvement, but some studies point to a primary muscle lesion [5]. This primary muscle involvement has been variably termed 'lepromatous myositis', 'leprous interstitial myositis' or leprous nodular interstitial myositis' [5]. Acid fast bacilli (AFB) has been demonstrated in the interstitium, inside macrophages, vessel walls and intramuscular nerves [6]. Initial presentation, as painless lymphadenopathy in lepromatous leprosy is uncommon and rarely biopsied. In studies where lymphadenopathy accompanies skin lesions, lymph nodes can show lepromas and acid-fast bacilli in $92.2 \%$ of cases and patchy fibrosis in $23.6 \%$ of the cases [7]. One study had inferred that lymph node biopsies might be more helpful for follow up of patients on treatment when skin biopsies were bacteriologically negative [8].

In recent times sensitivity of $\mathrm{M}$ leprae detection by polymerase chain reaction (PCR) has proven useful in cases where acid-fast staining does not detect bacilli [9]. In addition multidrug resistant strains can be detected by PCR, enabling institution of specific drug regimes [10].

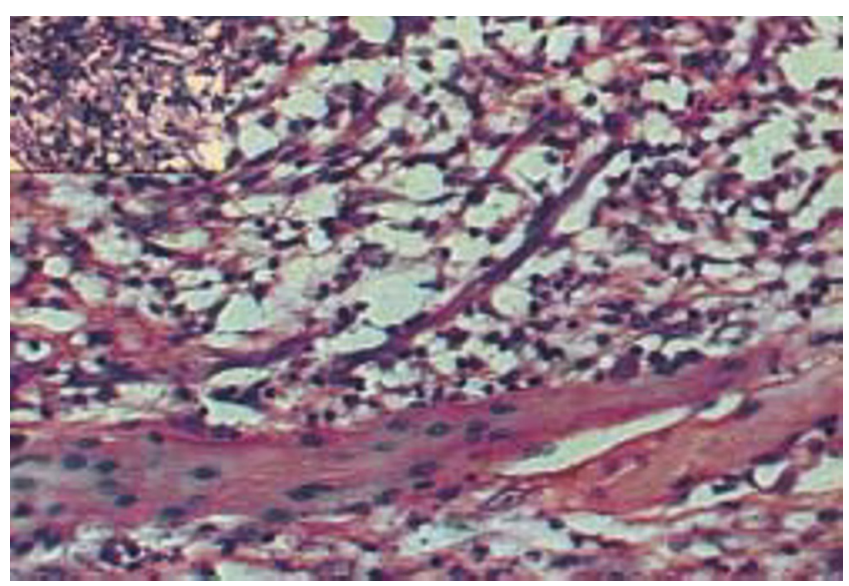

Fig. 3: Muscle biopsy showing diffuse sheets of foam cells splitting skeletal muscle fibres (H\&E x 40). Inset : AFB bacilli in globi in foam cells (Fite-Faraco stain $\mathrm{x} 10$ )

In conclusion, this report highlights the importance of systemic involvement in lepromatous leprosy especially when the initial presentation is with myositis or lymphadenopathy.

\section{Conflicts of Interest}

None identified

\section{References}

1. Park K. Park's Textbook of Preventive and Social Medicine. $16^{\text {th }}$ ed. Jabalpur : Banarasidas Bhanot, 2000.

2. Job CK. Pathology of leprosy. In: Hastings RS, Opromolla DVA, editors. Leprosy. $2^{\text {nd }}$ ed. Philadelphia: Churchill Livingstone, 1994; 190-233.

3. Ooi WW, Srinivasan J. Leprosy and the peripheral nervous system: basic and clinical aspects. Muscle Nerve 2004; 30: 393-409.

4. Yens, Diana A, Dimitrios J, Teitel A. Subcutaneous nodules and joint deformity in leprosy: Case report and review. Journal of Clinical Rheumatology 2003; 9: 181-6.

5. Werneck LC, Teive HA, Scola RH. Muscle involvement in leprosy study of the anterior tibial muscle in 40 patients. Arq Neuropsiquiatr 1999; 57: 723-34.

6. Kaur S, Malik AK, Kumar B. Pathological changes in striated muscles in leprosy. Lepr India 1981; 53:52-6.

7. Gupta JC, Panda PK, Shrivastava KK, Singh S. A histopathological study of lymph nodes in 43 cases of leprosy. Lepr India 1978; 50: 196-203.

8. Lele VR, Raichur BS, Grover S. Study of lymph node biopsies in lepromatous leprosy patients under treatment. Lepr India 1983; 55: 739-42.

9. Sugita Y. PCR in Leprosy. Nihon Hansenbyo Gakkai Zasshi 2001; 70:3-13.

10. Kim SH, Cho D, Kim TS. Detection of gene mutations related with drug resistance in Mycobacterium leprae from leprosy using Touch down (TD) PCR. FEMS Immunology and Medical Microbiology 2003; 36: 27-32. 